\title{
THE DENTAL WORKFORCE IN NEW SOUTH WALES
}

\section{P.D. Barnard}

\section{Acting Head, Public Health Dentistry}

University of Sydney

Dental services in Australia account for about five per cent of national health expenditures and 0.4 per cent of Gross Domestic Product. The workforce required to deliver these dental services comprises dentists, dental specialists, dental therapists, dental hygienists, dental prosthetists, dental chairside assistants, receptionists and dental technicians. ${ }^{1}$ This article describes the size of the workforce in NSW, changes in the number of practitioners over the past 10 years, and sources of training.

\section{DENTISTS}

The majority of dentists in NSW have been trained at the University of Sydney through a five-year dental undergraduate course. In the 1970s and 1980s, there were around 90 to 100 graduates per year. In the 1990 s, the number of first-year entrants was progressively reduced to about 60 graduates per year. This number of graduates will be maintained when Sydney University becomes the first Australian dental school to introduce a four-year graduate dental course, which will be similar to the graduate medical program. ${ }^{1,2}$

There was a very strong demand for dental services prior to 1970 because of the high prevalence of dental caries. In the 1970s, there were as many dental graduates from overseas countries registered to practise as there were from Australian dental schools. At that time, the supply of dentists in NSW went from an undersupply to an oversupply in relation to demand from the public; consequently, the Regulations of the Dentists Act 1934 (NSW) were changed to restrict the registration of most overseas-trained dentists. At the same time, the prevalence of dental caries was beginning to decrease as a result of water fluoridation and the introduction of fluoride toothpaste.

With less dental caries to be treated, dentists are now able to provide a wider range of more sophisticated and specialised services to more people. However, it is expected that the ratio of dentists to the population will decline further in the future with the lower numbers graduating from the University of Sydney. ${ }^{1,2}$

There were 3,863 dentists registered in NSW in 1998, or 61.5 dentists per 100,000 population (Table 3). Not all dentists registered with the Dental Board of NSW are in active practice as many are either retired, currently not working, or overseas. The number of NSW Branch members of the Australian Dental Association (2,591) is a closer indicator of those who are currently practicing in NSW. However, the best estimates are provided by the Dental Statistics and Research Unit of the Australian
Institute of Health and Welfare at the University of Adelaide from their analysis of Australian Dental Practice Survey questionnaires sent out by the Dental Board of NSW. The AIHW publication, Dental Practitioner Statistics, Australia, 1994, indicates that 2,733 dentists (45.2 per 100,000 population) were practising in NSW. Of these, 84 per cent were in the private sector and 15 per cent in the public sector. About 10 per cent (264) of dentists were registered by the Dental Board as specialists, with more than half of these being orthodontists. ${ }^{1-3}$

The number of female dentists in practice in NSW has continued to increase. The majority are employed rather than self-employed, but the proportion of those selfemployed is increasing rapidly. In 1994, female dentists comprised 24 per cent of all dentists aged 30 to 39 years compared with only four per cent of those over 60 years of age. $^{3}$

There has always been a higher concentration of dentists in Sydney than in other areas of NSW. In 1994, the number of practising dentists per 100,000 population was 54.8 for Sydney and 29.6 for the rest of the state. ${ }^{4}$ The Australian Dental Practice Surveys indicate that practitioners outside of Sydney see more patients than their counterparts in Sydney. ${ }^{4}$

\section{DENTAL PROSTHETISTS}

Dental prosthetists supply and fit dentures directly to the public and are registered by the Dental Board of NSW. The number of registered prosthetists has increased marginally over the years from 343 in 1987 to 387 in 1998. Dental prosthetists are trained dental technicians who have received additional clinical training through the TAFE college at Redfern (about 10 graduates per year). With limited facilities for training dental prosthetists and the decreasing need and demand for full dentures in NSW, it is expected that their numbers will not increase. As well as private practice, dental prosthetists provide services to government funded denture schemes. ${ }^{1,2}$

\section{DENTALTHERAPISTS}

Dental therapists provide a range of preventive and dental treatment procedures and have been the backbone of school dental services provided by the NSW Health Department. Formerly called school dental nurses, then school dental therapists, there were only a few working with the NSW Health Department prior to Commonwealth funding to subsidise training in the 1970s. Commonwealth funds were later withdrawn, but at one time the NSW Health Department had three training schools and the number of therapists employed by the department in school dental services increased rapidly in the 1970s and 1980s. During the 1990s, dental therapists were able to provide care for a larger number of school children due to the reduction in 


\section{TABLE 3}

DENTAL WORKFORCE IN NEW SOUTHWALES: SUMMARY OF AVAILABLE STATISTICS ${ }^{1}$

\begin{tabular}{|c|c|c|c|c|c|}
\hline Type of personnel & Year & $\begin{array}{c}\text { Number } \\
\text { registered/listed }\end{array}$ & $\begin{array}{l}\text { Number } \\
\text { active }\end{array}$ & $\begin{array}{c}\text { Number per } \\
100,000 \text { population }\end{array}$ & $\begin{array}{c}\text { Number of } \\
\text { NSW graduates }\end{array}$ \\
\hline \multirow[t]{6}{*}{ Dentists } & 1978 & 2617 & & 52.2 & 94 \\
\hline & 1988 & 3691 & & 64.8 & 85 \\
\hline & 1994 & & 2733 & 45.5 & 91 \\
\hline & -Sydney & & 2048 & 54.8 & \\
\hline & -Other & & 685 & 29.6 & \\
\hline & 1998 & 3863 & & 61.5 & 51 \\
\hline \multirow[t]{3}{*}{ Dental prosthetists } & 1979 & 141 & & & \\
\hline & 1987 & 343 & 269 & & \\
\hline & 1998 & 387 & & & 10 \\
\hline \multirow[t]{3}{*}{ Dental therapists } & 1978 & & 132 & & 65 \\
\hline & 1987 & & 258 & & 32 \\
\hline & 1998 & & 200 & & 15 \\
\hline \multirow[t]{2}{*}{ Dental hygienists } & 1988 & 42 & & & \\
\hline & 1998 & 113 & & & \\
\hline \multirow[t]{2}{*}{ Dental technicians } & 1987 & 630 & 466 & & 23 \\
\hline & 1998 & 621 & & & 30 \\
\hline
\end{tabular}

dental caries, and the introduction of an assessment program (SOKS) enabled their services to reach more children. In 1998, 200 therapists were employed by the NSW Department of Health, and 15 were in their final year at the one remaining training school located at Westmead Hospital. The numbers employed are unlikely to increase. Recent proposals, if approved, would give dental therapists the right to practise under the direct supervision and control of dentists in private practice, and to receive additional training that would allow them to treat adults, both in the government and private sectors. ${ }^{1,2}$

\section{DENTAL HYGIENISTS}

Dental hygienists work under the direct supervision and prescription of registered dentists to provide a range of oral care services for adults, such as root planing, cleaning and scaling of teeth, and oral health education. They also assist dentists. The absence of a training facility in NSW has limited their numbers. The Dental Board of NSW conducts examinations and lists hygienists who meet the requirements of the Dentists Act 1989 (NSW). There were 42 hygienists in 1988 and this number had increased to 113 by 1998 . A number of dental hygienists practising in NSW were trained in South Australia; others received training in the United Kingdom, South Africa and the United States. There is a demand for these staff in both the private and the public sectors. ${ }^{1,2,5}$

\section{DENTALTECHNICIANS}

Dental technicians provide laboratory services and manufacture appliances to the prescription of dentists and dental prosthetists. Many are self-employed, but the majority work for commercial dental laboratories. Their numbers have remained fairly constant; 630 were registered under the Dental Technicians Registration Act 1975 (NSW) in 1987 and 621 in 1998. The number graduating from the course offered at TAFE was 23 in 1987 and 30 in 1998. Although their work has become more specialised in recent years, a large increase in their numbers is not anticipated. ${ }^{1,2}$

\section{DENTAL CHAIRSIDE ASSISTANTS}

Many dental chairside assistants are still trained on the job in both the private and government sectors, but fulland part-time courses are now offered at a number of TAFE colleges. About 300 people enrol and about 100 complete these courses each year in NSW. There is also a Dental Assistants Association Certificate, which is completed by 30 to 40 dental chairside assistants in NSW each year. Chairside assistants also often provide receptionist services for private dental practices. TAFE courses are available for dental health education and for radiography. On completion of the radiography course, chairside assistants can take radiographs. ${ }^{1,2}$

\section{THE AUSTRALIAN DENTAL ASSOCIATION}

The Australian Dental Association (ADA) carries out regular surveys of dental fees charged by their members in the private practice sector. The results are used by the ADA to negotiate the fixed-fee scale of the Commonwealth Government which is used as the basis for fees charged for work done for Repatriation beneficiaries. They also act as a guide for determining fixed fee scales by state governments. From time to time, 
the ADA also carries out dental practice surveys to determine the costs of private dental practices and the productivity of dentists in the private and government sectors. For example, in 1997, self-employed general practitioners averaged about 58 patient appointments per week, which was equivalent to 2,550 patient appointments per year with about 2.1 visits each for the 1,200 different patients seen. ${ }^{4}$

Many groups in the community, such as the elderly, those living in institutions, the rural disadvantaged, socially disadvantaged, the disabled, Aboriginal and Torres Strait Islander people, refugees, and migrants, have special dental needs. To meet these needs, dental services must be expanded and be provided by a more appropriately trained dental health workforce in both the private and government sectors. The NSW Department of Health, universities, and TAFE colleges can provide such training, which should include a focus on population health issues and the needs of special groups.

\section{REFERENCES}

1. Barnard PD. Facts and Figures in Australian Dentistry 1988. Sydney: Australian Dental Association Inc, 1989.

2. Australian Dental Association (NSW Branch). Dental manpower statistics as at July 1998. Sydney: Dental Health Education and Research Committee, 1998.

3. Szuster FSP, Spencer AJ. Dental practitioner statistics Australia, 1994. Dental Statistics and Research Series, No. 11, AIHW, University of Adelaide, 1997.

4. Barnard PD, White J, Australian dental practice survey 1997. Third report. Australian Dental Association News Bulletin 1999; 266: 13-21.

5. Szuster FSP, Spencer AJ. Dental hygienist labourforce Australia, 1996. Dental Statistics and Research Series, No. 12, AIHW, University of Adelaide, 1997. it

\section{LETTERS TO THE EDITOR}

\section{DEAR EDITOR,}

I thank the reviewers for their comments on my article (Volume 10, Number 3), and the NSW Public Health Bulletin for the opportunity to reply to those comments.

In their review of the principal academic references that suggest a link between periodontal disease and preterm birth, Drs Roberts and Algert state '...the Offenbacher article provides only weak evidence, if any, of a causal association between periodontal disease and preterm birth...' and that '... what the study literally shows is a very strong association between PLBW and a variable the authors have created...'

Firstly, this study can only establish an association. Evidence for causation would come from a prospective controlled clinical trial. This would entail periodontal treatment of many women, since preterm delivery is a relatively rare and unpredictable event. However, it is appropriate to establish an association before embarking upon a periodontal intervention study.

The reviewers sought an explanation of the variable used. The yes/no variable that was created involves clinical attachment loss (CAL). The 'yes' category applies to women with CAL of $+3 \mathrm{~mm}$ affecting 60 per cent or more of their dentition. The authors observe, correctly, that mean measures of CAL are often insensitive. They then create a variable that limits the effect of insensitivity. The 'yes' level of CAL is likely to be a true positive observation of severe periodontal disease. A strong association is shown between severe periodontal disease in a particular population and preterm delivery. Investigations to define risk groups and establish causality would be helpful.
In their review of the principal academic references that suggest a link between cardiovascular disease (CVD) and oral health, Professor Tofler and Dr Kull reviewed papers reporting on the link between periodontal disease and CVD in larger populations. I agree with their comments that strong associations exist between periodontal disease and CVD and that further studies are warranted to investigate the effect of treatment interventions.

\section{Barbara Anne Taylor}

Head, Department of Periodontics

United Dental Hospital of Sydney, Surry Hills

\section{DEAR EDITOR,}

Professor Tofler and Dr Kull rightly detail, in their comprehensive review of the putative association between periodontal and cardiovascular disease, ${ }^{1}$ the potential confounders which compromise the epidemiological evidence demonstrating the link between periodontal disease and CVD, including the risk factors that operate in both diseases, such as age, cigarette smoking and diabetes; and social factors which may be active in both diseases. However, as they pointed out, such confounders were adjusted for and still statistically significant associations were found between the two diseases. ${ }^{2}$ As they admitted, in theory, there are 'compelling biological links' between the proinflammatory effects of periodontal infection and the resultant CVD. However, randomised clinical trials would be close to impossible to construct, and the objective evidence linking the two diseases is most likely to come from strongly controlled epidemiological studies, as did 